\title{
Inequality for Wage Earners and Self-Employed: Evidence from Panel Data*
}

Pedro albarran $\dagger$, Raquel Carrasco $\$$ and MaIte Martinez-Granado $§$

†Departamento de Economía, Universidad Carlos III de Madrid, Getafe, Spain (e-mail:pedro.albarran@uc3m.es)

$\ddagger$ Departamento de Economía, Universidad Carlos III de Madrid, Calle Madrid 126

28903, Getafe, Spain (e-mail: raquel.carrasco@uc3m.es)

$\S N A I D E R$ and Departamento de Fundamentos del Análisis Económico II

Universidad del País Vasco, Bilbao, Spain (e-mail:maite.mtzgranado@ehu.es)

\section{Abstract}

In this paper we highlight the importance of analysing the evolution of income inequality separately for employees and self-employed workers. Using Spanish panel data on income and consumption for the period 1987-96, we find noticeable differences across these groups in the evolution of income inequality, and in the relative importance of the transitory and permanent components of income variance. The evolution of inequality is mainly explained by movements in the transitory component for the self-employed and by the permanent component for the employees. Our results suggest that different policies should be implemented for each group.

\section{Introduction}

The evolution of inequality has been widely analysed in the literature in recent years Many studies have tried to identify the contribution of permanent and transitory income shocks to the variation in inequality (Moffit and Gottschalk, 1995, 2002; Blundell and Preston, 1998). Accounting for these two different types of income 
shocks is crucial as they have very different implications for welfare and policy. In general, changes in the permanent component of income inequality have been associated with changes in the price of skills, while changes in the transitory componen have been related to income uncertainty, changes in labour market instability and measurement error.

Typically, in the literature, two distinct groups of workers have been pooled together: self-employed and employees. This can be problematic to the extent that employees and self-employed might receive different types of shocks and might cope with them in different ways. In particular, the volatility of their income shocks, that is, their income risk, will be, in general, different. Therefore, conclusions can be misleading as regards the evolution and decomposition of inequality when pooling self-employed and employee workers together. Given that many governments have promoted policies to foster self-employment as a way to alleviate unemployment it might as well be useful for policy-makers to take into account the possible side effects of such policies in terms of inequality.

The purpose of this paper is to identify the contribution of permanent and transitory shocks to the evolution of income inequality separately for households headed by self-employed or employee workers. The results are compared with the standard case, where this distinction is neglected. We measure inequality in terms of the variance of household income instead of individual wage rates. Household income is the relevant measure when analysing household inequality, as it allows accounting for crucial issues such as insurance among household members. ${ }^{.}$Following the approach proposed by Blundell and Preston (1998) and Blundell, Pistaferri and Preston (2008), we use the evolution of the variances and covariances of income and consumption to identify the parameters of interest, that is, the variance of the permanent and the transitory shocks to income.

The data we use are derived from the Spanish Family Expenditure Survey (Encuesta Continua de Presupuestos Familiares, ECPF hereafter). It is a rotating pane that covers the period 1986-97, containing information on income and consumption. Other microeconomic data used in most of the literature so far either lack the longitudinal dimension or the information on both income and consumption. For instance, Blundell and Preston (1998) use Family Expenditure Survey (FES) data from the UK, which contain only cross-sectional information on income and consumption. A the same household is not consecutively observed, they have to aggregate data to obtain a pseudo-panel for cohorts. Then, the variances of the shocks are identified only under some restrictive assumptions. Blundell et al (2008) combine US panel data on income from the Panel Study of Income Dynamics (PSID) with consumption data from repeated Consumer Expenditure Survey (CEX) cross-sections. They create

${ }^{1}$ Baker and Solon (2003) and Kalwij and Alessie (2007) use individual wage rates. This is convenient a one can directly relate the increase in inequality to, for instance, changes in the price of skills. Nonetheless, it overestimates the actual inequality in the economy because individual inequality is partly undone by intra-household agreements. a panel with income and imputed consumption, which introduces additional noise in data.

In this paper we overcome these problems by exploiting the unique characteristics of the ECPF: (i) the longitudinal dimension allows us to avoid cohort aggregation bias; and (ii) the information on consumption improves the efficiency of the estimates. The reason is that it provides extra moments for identification and allows estimating a richer model, as it is possible to identify the degree of insurance of consumption with respect to the income shocks. ${ }^{2}$

Our paper is also related to a different strand of the literature that has stressed the importance of accounting for heterogeneity between individuals when analysing income inequality (Guvenen, 2005; Primiceri and van Rens, 2006). Following a different methodology, Dickens (2000) analyses the covariance structure of individual earnings by cohorts in the UK and points out the differences in the evolution of permanent and transitory components across skill groups. Other papers have provided some evidence that employment status is an important factor in explaining inequality trends. For instance, Jenkins (1995) and Parker (1999) find that self-employment income changes are among the key explanations for the changes in inequality in the UK.

Our results show noticeable differences in the evolution of income inequality and in the relative importance of the permanent and transitory components for employees and self-employed. Specifically, we find that income inequality follows a similar pattern for employees and for the sample which includes self-employed, employees and unemployed. We also find that it often evolves in opposite directions for employees and self-employed over the sample period. These trends can be mainly explained in terms of the transitory component of income for the self-employed, although there is an increase in the variance of the permanent component for this group in the early 1990 s. For the employees, the evolution of inequality is mainly driven by the permanent component. The observed decrease in income inequality for this group at the end of the period is mainly due to a decrease in the variance of the transitory component. Given these disparities, it seems that incomes of employees and self-employed should be studied separately. Moreover, the results for the overall group, which are usually reported in the literature, provide a misleading idea of the patterns and trends affecting the self-employed.

The rest of the paper is structured as follows. Section II presents the theoretical framework and the identification strategy. Section III describes the data set used and discusses the evolution of income and consumption in the raw data. Section IV presents the results and section $\mathrm{V}$ concludes. ${ }^{2}$ Cutanda (2002) also uses the ECPF to decompose the changes in inequality into a permanent and
a transitory component. However, he does not exploit the panel dimension of the data and focuses on
differences in inequality across cohorts. Cervini and Ramos (2006) exploit the panel dimension of the Furopean Community Household Panel and analyse inequality for Spanish male earnings using only data on earnings. 


\section{Model}

In this section, we first describe the income process. As is customary, we assume that income is subject to both permanent and transitory shocks. In our case, these shocks will be different for self-employed and for employees. Secondly, we propose a standard linearized model of life-cycle consumption, which allows linking income shocks and consumption. Finally, we explain how permanent and transitory income shocks can be identified.

\section{Income dynamics}

We consider a stochastic process for the log of real income, $\ln Y$, given by:

$$
\ln Y_{i t}=\psi^{\prime} Z_{i t}+\lambda_{t}+\sum_{q=1}^{4} \eta_{i q} d_{q t}+P_{i t}+v_{i t},
$$

where $i$ denotes household, $q$ denotes season $(q=1, \ldots, 4$, for each quarter within a year $)$ and $t$ denotes time $(t=1986: I, 1986: I I, \ldots, 1996: I V, 1997: I) . Z_{i t}$ is a set of observable demographic characteristics and $\lambda_{t}$ is an aggregate shock that is picked up through time dummies. ${ }^{3}$ Variables $\eta_{i q}$ are individual-specific quarterly effects and $d_{q t}$ is a dummy that takes a value 1 if the observation in period $t$ corresponds to the quarter $q$ and 0 otherwise. The inclusion of these quarterly individual effects accounts for the particular payment system of some (but not all) employed workers in Spain. They get two extra payments per year, one in December and the other in July. The payment scheme for a given worker in our data set is unobservable for the econometrician and determined by his job. Thus it can be reasonably taken as exogenous to the individual's choices. In other words, the seasonal pattern of income can be modelled as varying randomly from one individual to another. ${ }^{4}$

The rest of the unexplained income is decomposed into two terms: a permanent component, $P$, and a transitory (mean-reverting) component, $v$. As in previous empirical studies (e.g. Blundell and Preston, 1998; Blundell et al., 2008), we assume that the permanent component follows a random walk of the form:

$$
P_{i t}=P_{i t-1}+\zeta_{i t},
$$

where $\zeta_{i t}$ is a random term orthogonal to $v_{i t}$. We also assume that $v_{i t}, \zeta_{i t}$ and $\eta_{i q}$ are orthogonal to the covariates. Their variances could in principle vary over time and across cohorts and education.

${ }^{3}$ In the vector $Z_{i t}$ we include cohort dummies and all their possible interactions with the time dummies. This is the most flexible model that controls for period, cohort and age effects and that can be estimated under parameters.

${ }^{4}$ This component of income is similar to the individual unobserved time-invariant heterogeneity in pane data models, but with inclusion of seasonal variation (see Albarrán, 2000; Alvarez, 2004, for further details). Therefore, it is predictable for the individual and it is not an unexpected shock.
Combining equations (1) and (2), it follows that income growth is

$$
\Delta \ln Y_{i t}=\psi^{\prime} \Delta Z_{i t}+\Delta \lambda_{t}+\sum_{q=1}^{4} \eta_{i q} \Delta d_{q t}+\zeta_{i t}+\Delta v_{i t}
$$

Our empirical specification of the income process allows for heterogeneity in two different ways, as the effect of observable factors $Z_{i t}$ on income and the variance of the shocks can be different for self-employed and employees.

\section{Consumption growth}

Under plausible assumptions about preferences for intertemporal consumption (see Browning and Lusardi, 1996), it can be shown that the optimal consumption growth can be expressed as:

$$
\Delta \ln C_{i t}=\frac{1}{\rho} \ln \left(r_{t}-\delta\right)+\frac{1}{\rho} \beta^{\prime} \Delta Z_{i t}+m_{i t}+\varsigma_{i t},
$$

where $C$ is consumption, $Z$ is a vector of demographic variables (taste shifters), and and $\delta$ are the real interest rate and the subjective discount rate, respectively. Variable $m_{i t}$ depends on the conditional variance of consumption, which can be interpreted as accounting for the precautionary motive for saving, and $\varsigma_{i t}$ is an innovation to consumption growth.

The innovation to consumption, $\varsigma_{i t}$, can be directly related to the innovations to income. In particular, we follow Blundell and Preston (1998) and Blundell et al. (2008) and assume that the precautionary saving component in equation (4) can be picked up by cohort, $j$, and time, $t$, specific constants, $\Gamma_{j t}$, plus some householdspecific deviation from these, $\varepsilon_{i t}$, which is white noise. Additionally, we assume that permanent shocks cannot be insured through precautionary saving and that the transitory shocks follow an $\mathrm{MA}(l)$ process,

$$
v_{i t}=\sum_{k=0}^{l} \vartheta_{k} u_{i t-k}
$$

with $\vartheta_{0} \equiv 1$. The order of the moving average, $l$, would be empirically determined.

Under these simplifying assumptions, we can derive the following equation that relates the growth of consumption to the permanent and transitory shocks to income:

$$
\Delta \ln C_{i t}=\Gamma_{j t}+\varepsilon_{i t}+\theta^{\prime} \Delta Z_{i t}+\zeta_{i t}+\varphi u_{i t},
$$

where the parameter $\varphi$ captures how transitory income shocks are transmitted to consumption growth (see Blundell et al., 2008, for further details). Notice that we assume that the permanent component of income cannot be insured by the households, while, in principle, the transitory component can be $(\varphi \leq 1)$.

\section{Decomposition of inequality}

The main parameters of interest are the variance of the permanent shock to income, $\operatorname{var}\left(\zeta_{i t}\right)$, and the variance of the transitory shock to income, $\operatorname{var}\left(u_{i t}\right)$. These variances 
could vary across a number of dimensions to capture the effect of period, age, cohort, education, employment status, etc. on income volatility. However, because of samplesize restrictions, we estimate only different variances for each year and employment status. As a robustness check, we allow for the variances to vary also across birth cohorts or education.

At this point, it is worth mentioning that when one analyses household income instead of individual earnings, it is not obvious that the canonical decomposition of period, age and cohort effects is so relevant. On the one hand, household surveys usually contain relevant variables like education, that are typically missing in the literature of wage inequality. But sample sizes are not generally very large, so in this case income variance includes only two of the effects at one time (period and cohort effects, or period and education effects); otherwise, the estimates would be very imprecise (see Blundell et al., 2008). On the other hand, factors related to insurable individual risks that determine individual earnings dispersion are no longer determinants of income inequality at the household level. For instance, it seems plausible to assume that the age of just one member of the family (the household head) does not affect the variance of household income.

Initially, we estimate only period and employment status effects in order to analyse if the evolution and decomposition of inequality are different according to employment status. At this stage, omitting cohort (or education) effects is problematic if period effects are biased differently for the employees and for the self-employed. However, it is likely that the business cycles affect all individuals in a similar fashion independently of their cohort, as all the individuals in our sample entered in a labour market strongly influenced by the Franco-era structure. Moreover, those differen cohort-period effects in individual earnings can be partly insured at the household level and, thus, they do not appear in the household income dispersion. Therefore, period (and cohort) effects can be interpreted as true-period (and cohort) effects in our analysis, despite the omission of age and education. In any case, the purpose of the robustness check is to analyse whether or not the differences between employees and self-employed persist when we include cohort or education effects.

The variances of interest are identified through a set of variance and covariance restrictions between income and consumption. First, we remove the effect of demographic characteristics and aggregate terms in income and consumption growth:

$$
\Delta y_{i t}=\sum_{q=1}^{4} \eta_{i q} \Delta d_{q t}+\zeta_{i t}+\Delta v_{i t},
$$

$\Delta c_{i t}=\varepsilon_{i t}+\zeta_{i t}+\varphi u_{i t}$

where

$$
\Delta y_{i t}=\Delta \ln Y_{i t}-\psi^{\prime} \Delta Z_{i t}-\Delta \lambda_{t} \quad \text { and } \quad \Delta c_{i t}=\Delta \ln C_{i t}-\Gamma_{j t}-\theta^{\prime} \Delta Z_{i t}
$$

Then we exploit the quarterly panel structure of the data and derive the following moment conditions:

$$
\begin{gathered}
\operatorname{cov}\left(\Delta y_{i t}, \Delta y_{i t+s}\right)= \begin{cases}\sum_{q=1}^{4} \operatorname{var}\left(\eta_{i q}\right) \Delta d_{t q}^{2}+\operatorname{var}\left(\zeta_{i t}\right)+\operatorname{var}\left(\Delta v_{i t}\right) & \text { for } s=0 \\
\sum_{q=1}^{4} \operatorname{var}\left(\eta_{i q}\right) \Delta d_{t q} \Delta d_{t+s, q}+\operatorname{cov}\left(\Delta v_{i t}, \Delta v_{i t+s}\right) & \text { for } s \neq 0\end{cases} \\
\operatorname{cov}\left(\Delta c_{i t}, \Delta c_{i t+s}\right)= \begin{cases}\operatorname{var}\left(\varepsilon_{i t}\right)+\operatorname{var}\left(\zeta_{i t}\right)+\varphi^{2} \operatorname{var}\left(u_{i t}\right) & \text { for } s=0 \\
0 & \text { for } s \neq 0\end{cases} \\
\operatorname{cov}\left(\Delta c_{i t}, \Delta y_{i t+s}\right)= \begin{cases}\operatorname{var}\left(\zeta_{i t}\right)+\varphi \operatorname{var}\left(u_{i t}\right) & \text { for } s=0 \\
\varphi \operatorname{cov}\left(u_{i t}, \Delta v_{i t+s}\right) & \text { for } s \neq 0 .\end{cases}
\end{gathered}
$$

As can be seen from the set of conditions (8)-(10), this strategy involves the estimation of the variance of the seasonal effects (four additional nuisance parameters). Alternatively, we could recursively use equation (2) to obtain a fourth differences specification in which the nuisance parameters are dropped out. ${ }^{5}$ Under that approach, only individuals that had been at least for five consecutive periods in the sample could be used and more than $15 \%$ of the sample observations would be dropped. Therefore, our preferred strategy is to use the set of conditions based on the first differences of the consumption and income equations. The estimates of the variances through the set of conditions in fourth differences have been calculated as a robustness check of our results.

These moments are computed separately for employees and self-employed. Estimation is done by (equally weighted) minimum distance. Empirical results remain unchanged when using diagonally weighted minimum distance and optimal minimum distance.

The availability of panel data has several advantages over a repeated crosssectional analysis. In the latter case, strong assumptions need to be made to identify the parameters of interest. In particular, one needs to assume cross-sectional orthogonality of consumption and income to past shocks, lack of serial correlation in transitory shocks, and lack of measurement error in consumption and income. Under previous assumptions it is possible to separate the growth in the variance of transitory shocks from the variance of permanent shocks. Nonetheless, it is necessary to assume that aggregate consumption and income are part of the consumer's information set, and that this assumption is not an application of the permanent income hypothesis (see Deaton and Paxson, 1994; Blundell and Preston, 1998). With panel data, identification does not require making such assumptions. Moreover, although with panel data identification of the variances of shocks to income strictly requires only data

${ }^{5}$ In that case we obtain:

$\Delta_{4} \ln Y_{t t}=\psi^{\prime} \Delta_{4} Z_{i t}+\Delta_{4} \lambda_{t}+\zeta_{i t}+\zeta_{i t-1}+\zeta_{i t-2}+\zeta_{i t-3}+\Delta_{4} v_{i t}$, which does not contain seasonal effects, although introduces higher persistence with respect to the immediate previous periods. 
on income, consumption (which is closely related to permanent income) provides an additional source of relevant information. Thus, the joint use of panel data on consumption and income gives a richer set of overidentifying restrictions and improves efficiency of the estimates. As a by-product, it also allows for the estimation of other interesting parameters like the variance of the consumption shock, $\operatorname{var}\left(\varepsilon_{i t}\right)$, and the degree of insurability of the transitory shocks, $\varphi$.

At this point, a few words are due regarding the identification of the parameters of interest if consumption and income were subject to measurement error. The variance of the permanent component is identified under the presence of classical measurement error (additive and independent) either in log income or in log consumption. The only requirement is that the measurement error of log income is not correlated with the measurement error of log consumption.

With respect to the transitory component, the presence of measurement error in $\log$ consumption does not affect its identification. The variance of the measuremen error could be separately identified from the variance of the consumption shock, $\operatorname{var}\left(\varepsilon_{i t}\right)$, through the correlation between the growth in log consumption in $t$ and $t+1$. Nonetheless, we do not estimate them separately as $\operatorname{var}\left(\varepsilon_{i t}\right)$ is not among our main parameters of interest. The presence of measurement error in log income is more problematic, as the estimated variance of the transitory component would be a mixture of the variance of the true transitory component and the variance of the measurement error. Unfortunately, it is not possible to disentangle both. So in the presence of measurement error in income, the variance of the transitory component would be overestimated. This problem is likely to be more important among the selfemployed, for whom income is usually measured more noisily (see Blundell et al., 2008).

\section{Data}

This section is divided in two subsections. First, we describe the data set and sample selection. Our samples for self-employed and employees include only those households whose head is in the same activity (either self-employment or employment) for three consecutive quarters. We also carried out estimates for the usual sample selection in the literature, which includes households whose head is, at a given period, self-employed, employee or unemployed; we call this sample 'All'. Secondly, we present some descriptive statistics of the three samples.

\section{The data set}

The data we use come from the Spanish Family Expenditure Survey (ECPF) that covers the period between the first quarter of 1985 and the first quarter of 1997. The ECPF is a rotating panel conducted by the National Institute of Statistics (INE). Of the approximately 3,100 households interviewed, one-eighth is replaced every quarter by a new fresh sample. As a result, we can follow up a household for a maximum of eigh consecutive quarters. As the purpose of the ECPF is to compute the CPI for Spain, it contains comprehensive information on expenditure and detailed information on income and demographic characteristics of households.

We define consumption as quarterly household expenditure on non-durable goods. It is the sum of expenditure on food, drinks, tobacco, clothing, footwear, energy and transport. Our data set also contains information on expenditure on durable goods, but not on consumption of service flows. As this is the relevant measure, we exclude expenditures on durable goods from our measure of consumption.

Income is defined as the quarterly monetary income earned by any member of the household net of taxes. We exclude the returns from capital and income from assets, as typically these are not precisely measured in survey data ${ }^{6}$ This means that for the self-employed our measure of income includes the part of the net profits that these individuals draw from their business in the form of salary and excludes capital gains or losses.

Income and consumption variables are in real 1992 pesetas, deflated by the CPI published by the INE. Both variables are adjusted onto comparable basis for different families using equivalence scales based on McClements (1977) that account for the number of adults and children in various age ranges.

Our unit of analysis is the household, and not the individual. The reason is that many decisions, such as labour force participation and employment status of family members, are taken at the household level, which allows for insurance within the household.

A household is classified as self-employed (employed) in period $t$ when its head receives income from self-employment (paid-employment) in that period. Few households whose head declares receiving both types of income are excluded from their respective samples (although they are kept in the sample of 'All'). Using households' heads to characterize households' employment status seems reasonable as in our sample around $80 \%$ of the household income is earned by the household head. Additionally, most self-employed in our data have a wife who, if working, is also selfemployed, while most employees have a wife who, if working, is also an employee (see Table 2)

The step-by-step selection of our sample is illustrated in Table 1. We focus on households headed by a male at working age during the sample period. We eliminate households with permanent visitors or that experience a change in their structure over the sample period. We also exclude households for which relevant information is missing and the heads of which work in the agricultural sector, given the particular characteristics of self-employment in this sector. Finally, we select households

${ }^{6}$ The comparison of income and consumption between the ECPF and the National Accounts shows that: (i) the levels are systematically lower for income, specially capital income, and for some items of consumption ${ }^{7}$ An altermative definition could be to consider as self-employed those households whose main source of total household income comes from self-employment. Nonetheless, an advantage of our criterion is that it permits to capture clearly the characteristics of the self-employed and to have a clean comparison of the choice between self-employment and other alternative. 
TABLE 1

TABLE 2

Sample selection: number of observations

Sample statistics

\begin{tabular}{lcc}
\hline & No. dropped & No. remaining \\
\hline Initial sample (1985 1st quarter to 1997 1st quarter) & 0 & 151,793 \\
Not fully interviewed & 33,586 & 118,207 \\
Aged 65 or more & 29,673 & 88,534 \\
With permanent visitors & 547 & 87,987 \\
Female head & 12,526 & 75,461 \\
Change in marital status & 354 & 75,107 \\
Change in family composition bigger than 1 & 1,236 & 73,871 \\
Invalid income & 2,164 & 71,707 \\
Invalid consumption & 721 & 70,986 \\
Born before 1920 or after 1964 & 2,187 & 68,799 \\
Ever in agriculture & 7,530 & 61,269 \\
Interviewed < & 5,417 & 55,852 \\
No. obs. sample employees (E) & \multicolumn{2}{c}{30,889} \\
No. obs. sample self-employed (SE) & \multicolumn{2}{c}{5,535} \\
No. obs. sample all & \multicolumn{2}{c}{55,852} \\
\hline
\end{tabular}

\begin{tabular}{|c|c|c|c|c|c|c|}
\hline \multirow[b]{2}{*}{ Variable } & \multicolumn{2}{|l|}{$E$} & \multicolumn{2}{|l|}{$S E$} & \multicolumn{2}{|l|}{ All } \\
\hline & Mean & $S D$ & Mean & $S D$ & Mean & $S D$ \\
\hline Age & 42.258 & 9.540 & 44.958 & 9.979 & 45.327 & 11.041 \\
\hline Cohort 1920-34 & 0.124 & 0.330 & 0.189 & 0.392 & 0.241 & 0.428 \\
\hline Cohort 1935-44 & 0.227 & 0.419 & 0.252 & 0.434 & 0.222 & 0.416 \\
\hline Cohort 1945-54 & 0.356 & 0.479 & 0.326 & 0.469 & 0.298 & 0.457 \\
\hline Cohort 1955-64 & 0.293 & 0.455 & 0.232 & 0.422 & 0.239 & 0.426 \\
\hline Without studies & 0.084 & 0.278 & 0.104 & 0.305 & 0.149 & 0.356 \\
\hline Primary education & 0.613 & 0.487 & 0.709 & 0.454 & 0.612 & 0.487 \\
\hline Secondary education & 0.175 & 0.380 & 0.123 & 0.329 & 0.139 & 0.346 \\
\hline University education & 0.128 & 0.334 & 0.064 & 0.246 & 0.100 & 0.300 \\
\hline Married & 0.965 & 0.184 & 0.969 & 0.175 & 0.955 & 0.207 \\
\hline Number of childre & 1.505 & 1.119 & 1.408 & 1.177 & 1.323 & 1.174 \\
\hline Popul. $<10,000$ & 0.176 & 0.381 & 0.284 & 0.451 & 0.216 & 0.411 \\
\hline Popul. 10-50,000 & 0.194 & 0.395 & 0.255 & 0.436 & 0.219 & 0.414 \\
\hline Popul. 50-500,000 & 0.466 & 0.499 & 0.353 & 0.478 & 0.419 & 0.493 \\
\hline Popul. $>500,000$ & 0.164 & 0.371 & 0.108 & 0.311 & 0.146 & 0.353 \\
\hline Full-time worker & 0.976 & 0.152 & 0.962 & 0.192 & 0.783 & 0.412 \\
\hline Wife employed & 0.252 & 0.434 & 0.152 & 0.359 & 0.224 & 0.417 \\
\hline Wife SE & 0.043 & 0.203 & 0.134 & 0.341 & 0.059 & 0.236 \\
\hline No. observations & & 30,889 & & 5,535 & & 55,852 \\
\hline No. households & & 6,138 & & 1,494 & & 9,292 \\
\hline
\end{tabular}

interviewed at least for three consecutive quarters, as this is the minimum time length needed to apply the moment conditions described in the previous section. The final sample of employees contains 30,889 observations and 6,138 households, the sample of self-employed contains 5,535 observations and 1,494 households, and, finally, the sample of heads either in self-employment, employment or unemployment contains 55,852 observations and 9,292 households. For each sample, this represents on average 997,197 observations and 1,660 households per year.

\section{Descriptive analysis}

Table 2 shows the descriptive statistics for the three samples. As can be seen, selfemployed household heads are on average older and less educated than employees. Regarding occupation, unfortunately the ECPF distinguishes only among selfemployed with employees and professionals, and self-employed without employees. Most of the self-employed in our sample (75.2\%) belong to the latter category. To reinforce this issue, we use a comparable sample from the Spanish Labour Force Survey (EPA). According to the EPA, in the period considered, self-employment is relatively more frequent in retailing and construction, while employment is more frequent in services and manufacturing. Table 3 presents the distribution of selfemployed and employees across occupational groups for the period 1994-97. ${ }^{8}$ Most self-employed are managers of small business or skilled workers. The percentage of professionals has increased in both groups, although they represent a larger proportion

${ }^{8}$ In 1994 there was a change in the National Classification of Occupations (CNO) and it is not possible to link data from 1994 onwards with data from previous years.

No. households

$$
6,138
$$

of employees than of self-employed. According to these figures it seems that heterogeneity among the self-employed is not bigger than among employees.

According to the EPA, around $24 \%$ of the working male population is selfemployed in Spain for the period considered; this figure is well above the average in Organization for Economic Cooperation and Development (OECD) countries (in US, UK and EU15 the average self-employment rates are $7.48 \%, 11.88 \%$ and $12.82 \%$, respectively). We find a similar evolution and magnitude of this rate in our data. Figure 1 shows that the percentage of self-employed has been generally higher in those households in the lower tail of the consumption distribution (below the 20th percentile) and has increased more among those in the upper part of the distribution (above the 80th percentile).

Table 4 provides a description of the distribution of income and consumption for the three samples over the whole period. It shows that, except for the 99 th percentile, household income of the self-employed is consistently below and exhibits greater dispersion than that of employees (Carrington, McCue and Pierce, 1996; Hamilton, 2000, find a similar pattern for the US). It is worth noticing that we measure total income and not earnings per hour. We roughly account for the number of hours by including a dummy for full-time employment of the household head in the income process. Thus, our measure of risk is net of the possible insurance through the household 
TABLE 3

Type of occupation

\begin{tabular}{|c|c|c|c|c|}
\hline Year & 1994 & 1995 & 1996 & 1997 \\
\hline \multicolumn{5}{|l|}{$S E$} \\
\hline Managers & 36.12 & 38.84 & 38.18 & 39.84 \\
\hline Professionals & 11.50 & 11.98 & 13.36 & 13.52 \\
\hline Clerks & 1.40 & 1.22 & 1.07 & \\
\hline Workers in acc. food services & 1.07 & 0.78 & 0.76 & 0.70 \\
\hline Personal services & 1.50 & 1.66 & 1.05 & \\
\hline Sales workers & 1.40 & 0.78 & 0.67 & 0.56 \\
\hline Craft and related trades & 15.64 & 15.13 & 16.06 & 15.72 \\
\hline Skilled mining workers and similars & 8.44 & 7.06 & 6.98 & 7.79 \\
\hline Skilled manufacturing workers & 7.26 & 6.60 & 6.08 & 5.55 \\
\hline Plant machine operators and assemblers & 13.15 & 13.15 & 13.15 & 12.07 \\
\hline Domestic service & 0.24 & 0.29 & 0.17 & 0.29 \\
\hline Unskilled workers & 2.28 & 2.50 & 2.47 & 2.15 \\
\hline \multicolumn{5}{|l|}{ E } \\
\hline Managers & 4.15 & 4.17 & 4.36 & \\
\hline Professionals & 18.69 & 20.17 & 22.37 & 23.02 \\
\hline Clerks & 11.01 & 10.17 & 9.74 & 9.67 \\
\hline Workers in acc. food services & 2.70 & 2.72 & 2.82 & 2.73 \\
\hline Personal services & 4.95 & 5.24 & 5.62 & 5.81 \\
\hline Sal & 2.92 & 2.69 & 2.68 & 2.69 \\
\hline ted trad & 11.15 & 11.78 & 11.54 & 12.34 \\
\hline and simil & 11.54 & 11.01 & 10.76 & 10.36 \\
\hline ufacturing workers & 4.21 & 3.99 & 3.64 & 3.76 \\
\hline Plant machine operators and assemblers & 17.67 & 17.71 & 16.66 & 16.13 \\
\hline Domestic service & 0.73 & 0.63 & 0.61 & 0.59 \\
\hline Unskilled workers & 10.27 & 9.73 & 9.19 & 8.22 \\
\hline
\end{tabular}

(a) Force Survey).

, age between 20

and 1964 . No observations: 84,521 .

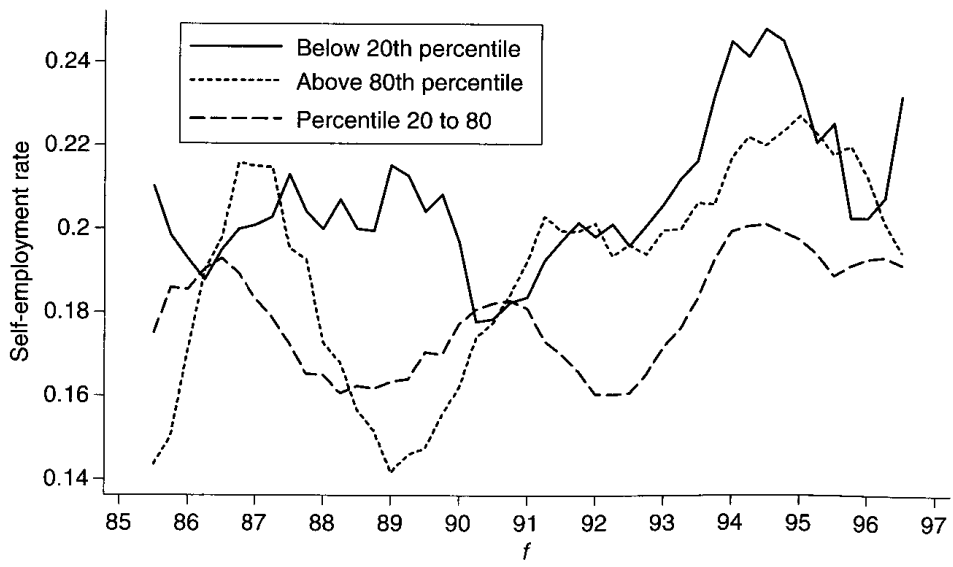

Figure 1. Self-employment rates by $\log ($ consumption) distribution
TABLE 4

Distribution of income and consumption

\begin{tabular}{|c|c|c|c|c|c|c|}
\hline & \multicolumn{3}{|l|}{ Income } & \multicolumn{3}{|c|}{ Consumption } \\
\hline & E & $S E$ & All & $E$ & $S E$ & All \\
\hline Mean & 387,418 & 354,491 & 357,971 & 229,860 & 225,704 & 221,835 \\
\hline Std. Dev. & 215,014 & 322,720 & 236,747 & 116,532 & 121,700 & 118,754 \\
\hline 1st percentile & 116,580 & 89,326 & 76,854 & 66,601 & 62,599 & 59,135 \\
\hline 25th percentile & 247,147 & 212,521 & 218,574 & 153,173 & 144,678 & 144,770 \\
\hline 50th percentile & 333,723 & 297,464 & 305,757 & 206,554 & 197,059 & 197,873 \\
\hline 75th percentile & 470,349 & 420,496 & 436,695 & 279,112 & 276,244 & 269,867 \\
\hline 99th percentile & $1,139,339$ & $1,173,133$ & $1,128,818$ & 621,412 & 657,816 & 621,800 \\
\hline
\end{tabular}

labour supply. This implies that self-employed households might have already insured their higher risk in earnings per hour by working more hours (see Parker, Belghitar and Barmby, 2005). Furthermore, consumption is also lower and more volatile for self-employed than for employees, although the differences are less pronounced than for income. As consumption is less subject to under-reporting than income, this fact could suggest that it is not only measurement error which drives the differences in income.

\section{Results}

We first show the general evolution of inequality in Spain for our sample period and compare trends for employees and self-employed. Then, we discuss the relative importance of permanent and transitory shocks in explaining such trends for each group. Finally, we carry out some robustness checks to analyse whether the different pattern found for employees and self-employed is also present in groups defined according to year-of-birth cohort and education.

\section{Income and consumption inequalit}

Figure 2 shows the paths of the cross-sectional variances of log income and log consumption for the three samples. It can be seen that the self-employed have higher income and consumption inequality than those of the other two groups, this being evidence of the greater risk this group faces. It is also noticeable that the variance of consumption is in general below the variance of income, which might reflect the fact that individuals are able to insure (at least partially) the risk associated with their occupations. Finally, consumption inequality tracks more closely income inequality for employees than for the other two samples.

Specifically, for the sample that includes all households income inequality tended to decrease during the late 1980s and to increase from 1992 to 1994 . After this point it decreased again. However, the variance of consumption remained approximately constant over the whole period. 


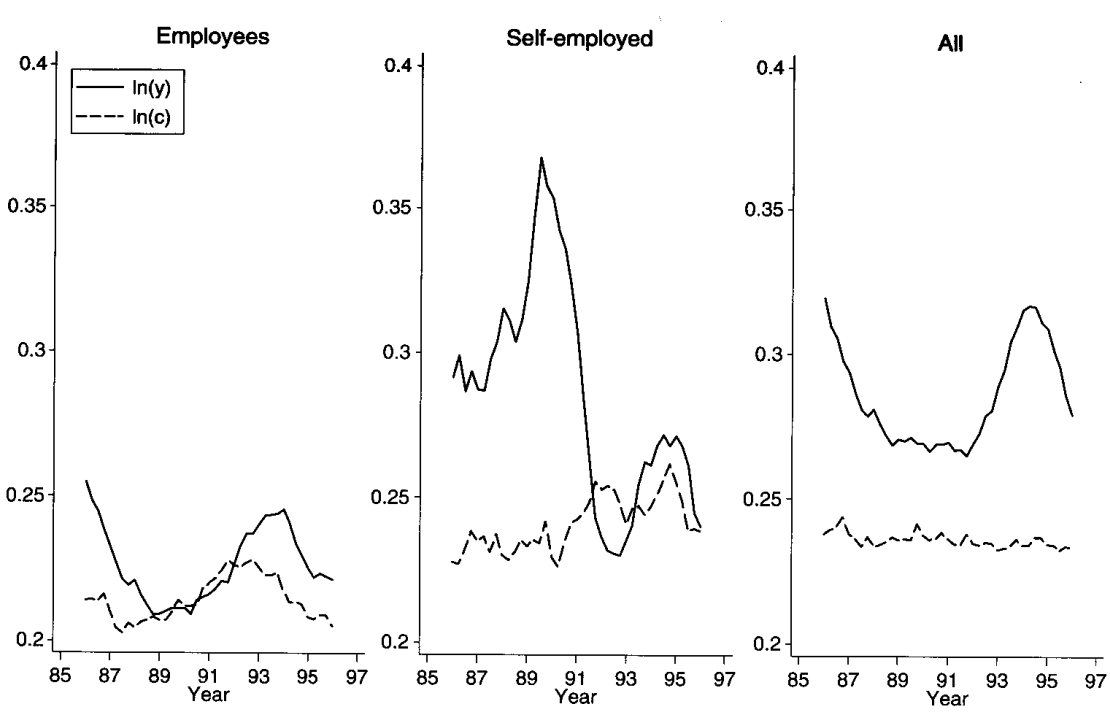

Figure 2. Variances of $\log ($ income) and $\log ($ consumption)

A different picture is obtained when we distinguish by employment status. As expected, income inequality for employees follows a pattern similar to that of the sample of all households, with two main differences: the level is lower, as the unemployed and self-employed are excluded from this sample, and the 1992 increase is less marked. However, the differences in consumption inequality are substantial, as for this group it co-moves with the variance of income. On the other hand, for the self-employed the pattern of income inequality presents two distinctive periods. Before 1992 it is very different from the one found for the other two samples. It is characterized by a strong initial increase and thereafter by a strong decrease. After 1992, the evolution is more similar to that of the sample of all individuals. The variance of consumption remains more or less flat up to 1992 and experiences a slight increase since then. Given this difference in evolution, it seems reasonable to analyse self-employed households separately.

\section{Estimation results: permanent and transitory inequality}

We follow the procedure described in section II to decompose income inequality into a permanent and a transitory component. We first remove the deterministic effect of observable characteristics on income and consumption. For that, we regress $\log$ income and $\log$ consumption on dummies for marital status, full-part time employment of the head, occupation of the wife, population size and time dummies. Specifically, we pick up $\lambda_{t}$ in equation (1) by including dummies for year and week. Separate regressions are carried out for households according to heads' year
TABLE 5

Test of joint significance of variances and covariances

\begin{tabular}{|c|c|c|c|c|c|c|c|c|c|}
\hline & \multicolumn{3}{|l|}{$E$} & \multicolumn{3}{|l|}{$\underline{S E}$} & \multicolumn{3}{|l|}{ All } \\
\hline & $\overline{\chi_{d f}^{2}}$ & $d f$ & $P$-value & $\overline{\chi_{d f}^{2}}$ & $d f$ & $P$-value & $\chi_{d f}^{2}$ & $d f$ & $P$-value \\
\hline \multicolumn{10}{|c|}{$\operatorname{cov}\left(\Delta c_{i t}, \Delta c_{i, t+s}\right)$} \\
\hline$s=0$ & $4,998.34$ & 45 & 0.000 & 974.81 & 45 & 0.000 & $7,670.26$ & 45 & 0.000 \\
\hline$s=1$ & $1,874.68$ & 44 & 0.000 & 284.51 & 44 & 0.000 & $2,983.61$ & 44 & 0.000 \\
\hline$s=2$ & 45.18 & 43 & 0.381 & 37.65 & 43 & 0.702 & 38.15 & 43 & 0.681 \\
\hline$s=3$ & 44.19 & 41 & 0.338 & 30.00 & 41 & 0.898 & 67.59 & 41 & 0.006 \\
\hline$s=4$ & 79.05 & 39 & 0.000 & 24.44 & 39 & 0.967 & 95.22 & 39 & 0.000 \\
\hline$s=5$ & 37.42 & 37 & 0.445 & 77.90 & 37 & 0.000 & 46.48 & 37 & 0.136 \\
\hline$s=6$ & 20.49 & 35 & 0.976 & 17.20 & 22 & 0.752 & 24.94 & 35 & 0.896 \\
\hline \multicolumn{10}{|c|}{$\operatorname{cov}\left(\Delta c_{i t}, \Delta y_{i, t+s}\right)$} \\
\hline$s=0$ & 116.46 & 45 & 0.000 & 69.82 & 45 & 0.010 & 210.11 & 45 & 0.000 \\
\hline$s=1$ & 37.18 & 44 & 0.757 & 51.71 & 44 & 0.198 & 55.27 & 44 & 0.119 \\
\hline$s=2$ & 46.69 & 43 & 0.323 & 41.15 & 43 & 0.552 & 48.08 & 43 & 0.275 \\
\hline$s=3$ & 58.37 & 41 & 0.038 & 32.93 & 41 & 0.811 & 33.11 & 41 & 0.805 \\
\hline$s=4$ & 29.85 & 39 & 0.854 & 27.46 & 39 & 0.917 & 30.68 & 39 & 0.827 \\
\hline$s=5$ & 33.73 & 37 & 0.623 & 19.42 & 37 & 0.992 & 37.47 & 37 & 0.447 \\
\hline$s=6$ & 21.02 & 35 & 0.970 & 12.35 & 22 & 0.950 & 30.80 & 35 & 0.671 \\
\hline \multicolumn{10}{|c|}{$\operatorname{cov}\left(\Delta y_{i t}, \Delta y_{i, t+s}\right)$} \\
\hline$s=0$ & $1,617.44$ & 45 & 0.000 & 499.20 & 45 & 0.000 & $1,777.69$ & 45 & 0.000 \\
\hline$s=1$ & 910.19 & 44 & 0.000 & 178.02 & 44 & 0.000 & 957.42 & 44 & 0.000 \\
\hline$s=2$ & 151.08 & 43 & 0.000 & 46.30 & 43 & 0.338 & 70.04 & 43 & 0.006 \\
\hline$s=3$ & 150.55 & 41 & 0.000 & 44.75 & 41 & 0.317 & 163.79 & 41 & 0.000 \\
\hline$s=4$ & 169.41 & 39 & 0.000 & 23.49 & 39 & 0.977 & 163.93 & 39 & 0.000 \\
\hline$s=5$ & 69.83 & 37 & 0.001 & 26.74 & 37 & 0.894 & 88.35 & 37 & 0.000 \\
\hline$s=6$ & 18.96 & 35 & 0.988 & 10.81 & 22 & 0.977 & 29.38 & 35 & 0.736 \\
\hline
\end{tabular}

of birth and education. We obtain the residuals of these regressions and, after taking first differences, exploit the set of restrictions in equations (8)-(10) for the samples of 'Self-Employed', 'Employees' and 'All'.'

Table 5 presents a battery of tests of joint significance of all the variances and covariances involved in equations (8)-(9). The figures in the table show that the restrictions imposed in equations (8)-(9) seem reasonable. Three points are worthy of mention. First, for employees and the sample of all households the autocovariances of income growth are significant to the fifth order, while for the self-employed only the first-order autocovariance is significantly different from zero. Both facts are compatible with the model proposed in section II, in which there is seasonality in income only for employees. Moreover, these results suggest that for the self-employed

${ }^{9}$ See Table 2 for cohort's definition and educational levels. Notice that although we work with equations in first differences, our specification allows us to control for differences in year of birth and education. The
reason is that the equations in levels are estimated for groups defined precisely in terms of year of birth and education and, moreover, time dummies are included in the specification in levels. 
TABLE 6

Minimum distance estimates

\begin{tabular}{lcccc}
\hline & & $E$ & $S E$ & All \\
\hline$\varphi$ & & -0.53682 & -0.08692 & -0.12487 \\
& & $(0.43964)$ & $(0.18558)$ & $(0.10638)$ \\
$\theta_{1}$ & & -0.12222 & 0.08692 & 0.03165 \\
& & $(0.16015)$ & $(0.10871)$ & $(0.05864)$ \\
$\theta_{2}$ & & 0.12753 & 0.02043 & 0.07793 \\
& & $(0.04551)$ & $(0.05730)$ & $(0.03108)$ \\
$\operatorname{var}\left(\left(_{i t}\right)\right.$ & & 0.17012 & 0.16010 & 0.17665 \\
& & $(0.00924)$ & $(0.00984)$ & $(0.00398)$ \\
$\operatorname{var}\left(\eta_{i 1}\right)$ & & 0.00486 & 0.00493 & 0.00507 \\
& & $(0.00109)$ & $(0.00534)$ & $(0.00126)$ \\
$\operatorname{var}\left(\eta_{i 2}\right)$ & & 0.00675 & 0.00174 & 0.00602 \\
& & $(0.00130)$ & $(0.00480)$ & $(0.00125)$ \\
$\operatorname{var}\left(\eta_{i 3}\right)$ & & 0.00604 & 0.00157 & 0.00826 \\
& & $(0.00124)$ & $(0.00299)$ & $(0.00148)$ \\
$\operatorname{var}\left(\eta_{i 4}\right)$ & & 0.00596 & -0.00577 & 0.00565 \\
& & $(0.00109)$ & $(0.00440)$ & $(0.00129)$ \\
$\operatorname{var}\left(\zeta_{i i}\right)$ & 1986 & 0.01296 & 0.00860 & 0.01005 \\
& & $(0.00539)$ & $(0.01216)$ & $(0.00416)$ \\
& 1987 & 0.00933 & 0.00956 & 0.00982 \\
& & $(0.00476)$ & $(0.01141)$ & $(0.00355)$ \\
& 1988 & 0.01082 & 0.00029 & 0.01176 \\
& & $(0.00408)$ & $(0.01272)$ & $(0.00376)$ \\
& 1989 & 0.01017 & 0.00654 & 0.01140 \\
& & $(0.00432)$ & $(0.01000)$ & $(0.00307)$ \\
& 1990 & 0.01738 & 0.00000 & 0.01250 \\
& & $(0.00473)$ & $(0.00872)$ & $(0.00334)$ \\
& 1991 & 0.01673 & 0.01240 & 0.01707 \\
& & $(0.00551)$ & $(0.00910)$ & $(0.00451)$ \\
& 1992 & 0.01280 & 0.01017 & 0.00879 \\
& & $(0.00482)$ & $(0.00812)$ & $(0.00364)$ \\
& 1993 & 0.01878 & 0.00974 & 0.01608 \\
& & $(0.00629)$ & $(0.00922)$ & $(0.00494)$ \\
& 1994 & 0.01257 & 0.01281 & 0.00962 \\
& & $(0.00590)$ & $(0.00890)$ & $(0.00455)$ \\
& 1995 & 0.01218 & 0.01691 & 0.01487 \\
& & $(0.00463)$ & $(0.00994)$ & $(0.00379)$ \\
& 1996 & 0.01678 & 0.00285 & 0.01219 \\
& & $(0.00430)$ & $(0.01016)$ & $(0.00372)$ \\
& 1997 & 0.01572 & 0.01678 & 0.01466 \\
& & $(0.00765)$ & $(0.01893)$ & $(0.00676)$ \\
& 1986 & 0.01538 & 0.02530 & 0.02958 \\
& & $(0.00555)$ & $(0.01219)$ & $(0.00534)$ \\
& 1987 & 0.01388 & 0.03975 & 0.02474 \\
& & $(0.00533)$ & $(0.01373)$ & $(0.00388)$ \\
& & 0.01061 & 0.06194 & 0.03114 \\
& & $(0.00386)$ & $(0.03164)$ & $(0.00524)$ \\
& & & & \\
& & &
\end{tabular}

TABLE 6

(continued)

\begin{tabular}{|c|c|c|c|}
\hline & $E$ & $S E$ & All \\
\hline 1989 & $\begin{array}{c}0.01291 \\
(0.00438)\end{array}$ & $\begin{array}{c}0.02148 \\
(0.00775)\end{array}$ & $\begin{array}{c}0.02149 \\
(0.00335)\end{array}$ \\
\hline 1990 & $\begin{array}{c}0.01196 \\
(0.00431)\end{array}$ & $\begin{array}{c}0.03764 \\
(0.01461)\end{array}$ & $\begin{array}{c}0.02523 \\
(0.00452)\end{array}$ \\
\hline 1991 & $\begin{array}{c}0.01543 \\
(0.00617)\end{array}$ & $\begin{array}{c}0.02421 \\
(0.00970)\end{array}$ & $\begin{array}{c}0.03164 \\
(0.00569)\end{array}$ \\
\hline 1992 & $\begin{array}{c}0.01198 \\
(0.00417)\end{array}$ & $\begin{array}{c}0.02797 \\
(0.00882)\end{array}$ & $\begin{array}{c}0.02599 \\
(0.00465)\end{array}$ \\
\hline 1993 & $\begin{array}{c}0.01973 \\
(0.00749)\end{array}$ & $\begin{array}{c}0.02065 \\
(0.00711)\end{array}$ & $\begin{array}{c}0.03769 \\
(0.00684)\end{array}$ \\
\hline 1994 & $\begin{array}{c}0.01609 \\
(0.00733)\end{array}$ & $\begin{array}{c}0.02753 \\
(0.00731)\end{array}$ & $\begin{array}{c}0.03412 \\
(0.00563)\end{array}$ \\
\hline 1995 & $\begin{array}{c}0.01139 \\
(0.00365)\end{array}$ & $\begin{array}{c}0.03066 \\
(0.00994)\end{array}$ & $\begin{array}{c}0.02585 \\
(0.00379)\end{array}$ \\
\hline 1996 & $\begin{array}{c}0.01093 \\
(0.00368)\end{array}$ & $\begin{array}{c}0.02118 \\
(0.00668)\end{array}$ & $\begin{array}{c}0.02607 \\
(0.00475)\end{array}$ \\
\hline 1997 & $\begin{array}{c}0.01050 \\
(0.00531)\end{array}$ & $\begin{array}{c}0.05422 \\
(0.01976)\end{array}$ & $\begin{array}{c}0.02398 \\
(0.00704)\end{array}$ \\
\hline
\end{tabular}

the transitory component has little or no persistence. Secondly, the first-order autocovariance of consumption growth is different from zero for the three samples. This can be interpreted as evidence of measurement error in consumption. Thirdly, for the three samples, the covariance between current consumption and current income growth is significantly different from zero, while the covariances between current consumption growth and future income growth are statistically equal to zero. This suggests that transitory shocks to income are not transmitted into consumption.

Table 6 presents the minimum distance estimates. Along the lines of previous studies we obtain statistically significant estimates for most of the parameters of interest. The variances of the seasonal component for the employees are also significant, while we do not find such an effect for the self-employed.

The estimates of the moving-average (MA) parameters $\left(\theta_{1}\right.$ and $\left.\theta_{2}\right)$ and the parameter $\varphi$ confirm the descriptive evidence shown in Table 5. Specifically, for the sample of employees and of all households there is evidence of an MA(2) and for the self-employed there is no persistence of the transitory shocks. The estimate for the parameter $\varphi$ is not significantly different from zero. This suggests that transitory income shocks are insured away by the households and only permanent income shocks are transmitted into consumption. Blundell et al. (2008) reach a similar conclusion using US data, although in their model they allow for partial insurance of the permanent component. Finally, the variance of consumption shocks is precisely estimated and accounts for a considerable amount of the cross-sectional variation in consumption. 
TABLE 7

Joint test of equality of variances

\begin{tabular}{lccc}
\hline & $E$ vs. $S E$ & $E$ vs. all & $S E$ vs. all \\
\hline $\operatorname{var}\left(\zeta_{\text {it }}\right)$ & 21.4412 & 7.7450 & 26.5671 \\
& $(0.0443)$ & $(0.8047)$ & $(0.0089)$ \\
$\operatorname{var}\left(u_{i i}\right)$ & 22.3141 & 25.8434 & 28.6047 \\
& $(0.0341)$ & $(0.0113)$ & $(0.0045)$ \\
\hline
\end{tabular}

Notes: Number in brackets are $P$-values.

The estimated variances of the transitory and permanent shocks are of similar magnitude for the employees. ${ }^{10}$ In turn, for the self-employed the variance of the transitory shock to the variation in inequality is larger than the variance of the permanent shock. This could partly be due to the fact that the estimated transitory componen incorporates the variance of the measurement error, which could be more important for self-employment income. But it is hard to believe that the measurement error evolve as much over time as to lead the time pattern of this component. Nonetheless, the permanent component for the self-employed is much lower than for employees and for the sample which includes unemployed workers, while the opposite occurs with the transitory component. Table 7 presents the $\chi_{12}^{2}$ tests of joint equality of permanent and transitory variances between samples. We find statistically significant differences for all cases, except for the permanent component between the sample of employees and 'All'.

In Figures 3 and 4 we plot the minimum distance estimates of the variance of the permanent and transitory shocks against time. The estimates are smoothed by taking 3-year moving averages. In general, Figure 3 points to an overall increase in the permanent inequality for the three samples. For employees, the increase (of around $45 \%$ ) stops by 1992 , remaining stable afterwards. For the self-employed, the increase is stronger and lasts until 1994. Overall, the variance of the permanent component for the self-employed doubles between 1987 and 1996. Employees display a behaviour more similar to that of 'All' than that of the self-employed. The evolution of the transitory component (Figure 4) displays a clear co-movement with the business cycle, although it is of different signs for employees and self-employed. While the Spanish economy slowed down from 1987 until the 1991-92 crisis, the transitory component increased by $23 \%$ for employees and by $14 \%$ for the sample of all households. This is more than compensated by the decrease observed during the recovery period (1992-96). On the other hand, for the self-employed the variance of the transitory component is clearly pro-cyclical: it decreased by $43 \%$ in the $1987-92$

${ }^{10}$ The quarterly structure of our data would allow us to estimate quarterly variances. But we have estimated

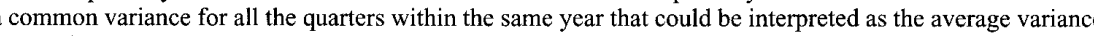
across the yer.

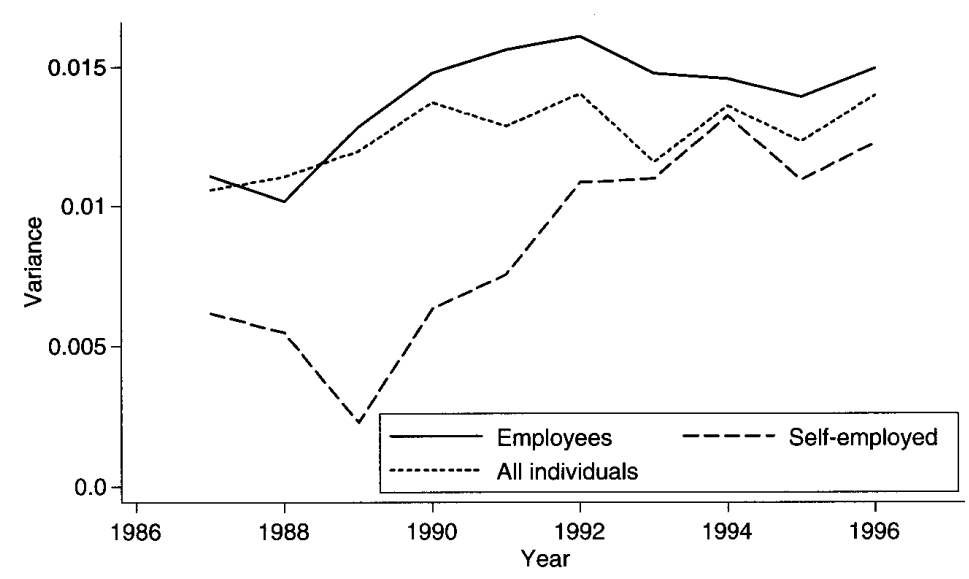

Figure 3. Variance of the permanent component

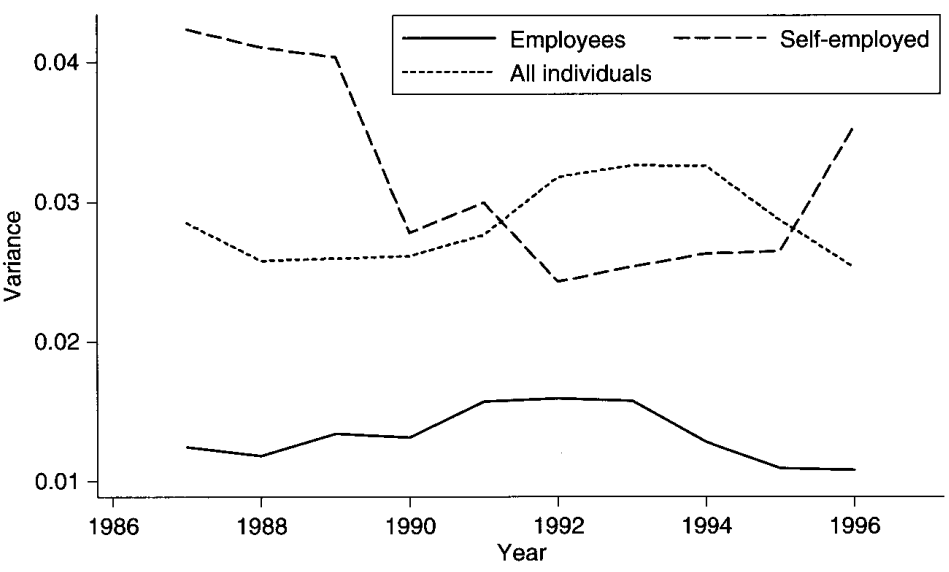

Figure 4. Variance of the transitory component

period and increased by around $46 \%$ thereafter. ${ }^{11}$ The increase in the variance of the transitory component for the samples of employees and 'All' also coincides with a period of higher employment instability in Spain because of the widespread use of temporary contracts introduced around 1984. The reduction from 1993-94 coincides with the implementation of additional labour market reforms aimed at reducing the indiscriminate use of this type of contracts.

${ }^{11}$ We find that the transitory component of income inequality is negatively (positively) correlated with the GDP growth for the employees (self-employed). The estimated correlation coefficients are -0.5522 (st. erro GDe 0.5510 (st enor 0.0634$)$, respectively. 
Our results show that the relative contribution of the transitory component to the self-employed is around $80 \%$ over the whole period, although with a decline during 1989-92. In turn, for the employees it fell from 55\% in the period 1986-89 to around $40 \%$ in the period $1996-97$. The decrease in income inequality for this group at the end of the period is mainly caused by a decrease in the variance of the transitory component. As the variance of the permanent component remains stable, this leads to a decrease in the relative importance of the transitory component.

To sum up, these results show that once we account separately for self-employed individuals, the picture of the evolution of the permanent and the transitory component of income shocks changes significantly. Similar conclusions are obtained when using the estimates from the specification in fourth differences for the employees and from the estimates using only income data (although in this case some of the effects become just marginally significant)

\section{Robustness check}

We have shown remarkable differences in the evolution and relative importance of inequality components for employees and self-employed. One could think that such differences are not genuinely driven by the employee or self-employed status, but by some other characteristics correlated with it, such as year-of-birth cohort and education. Although we have controlled for these variables in modelling the income process, one may wonder whether income inequality itself varies across cohorts and levels of education. Ideally, we would like to separately compute permanent and
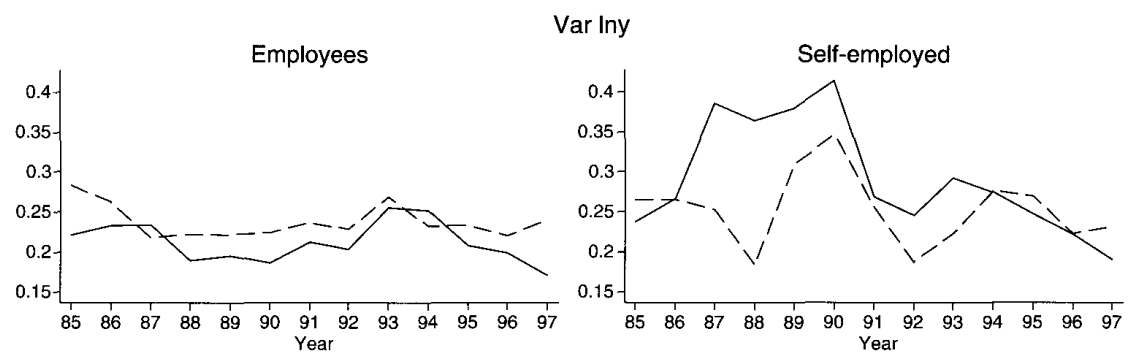

Var Inc

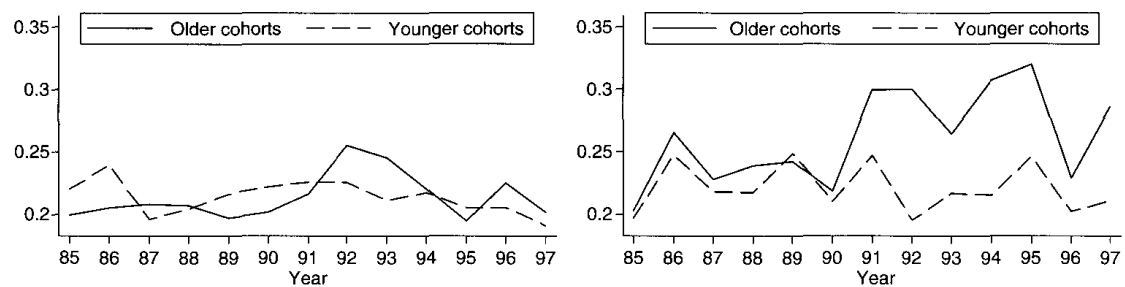

Figure 5. Variances of $\log$ (income) and $\log$ (consumption), by cohort
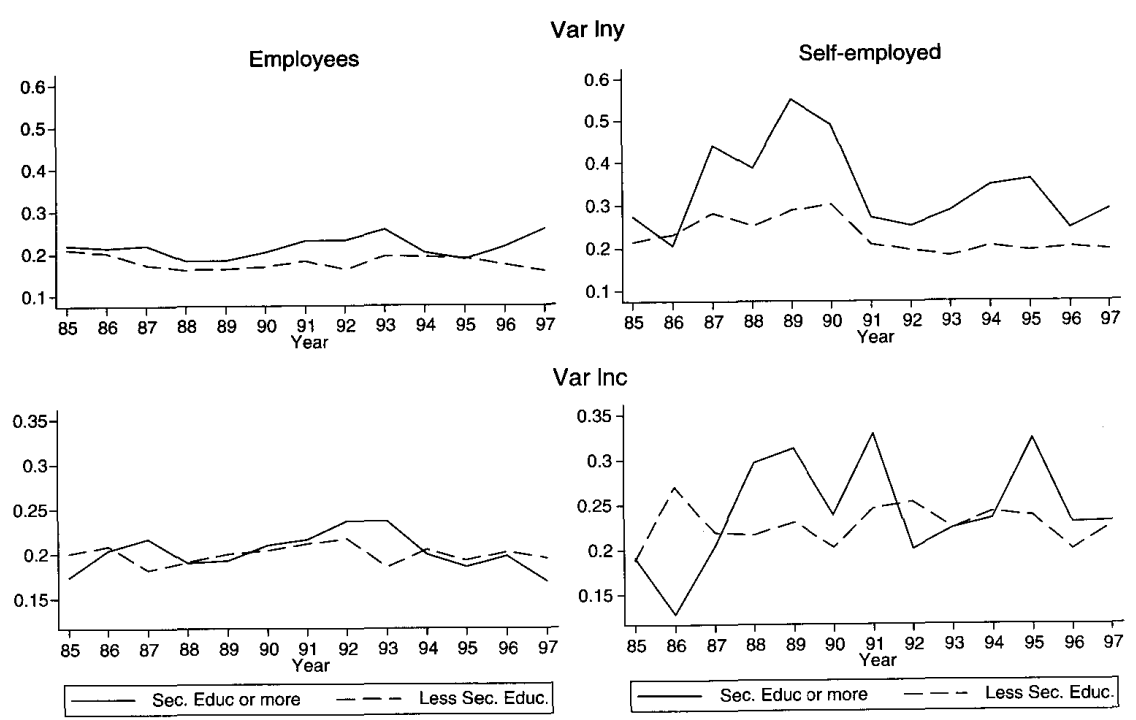

Figure 6. Variances of $\log$ (income) and $\log ($ consumption), by education

Older cohorts
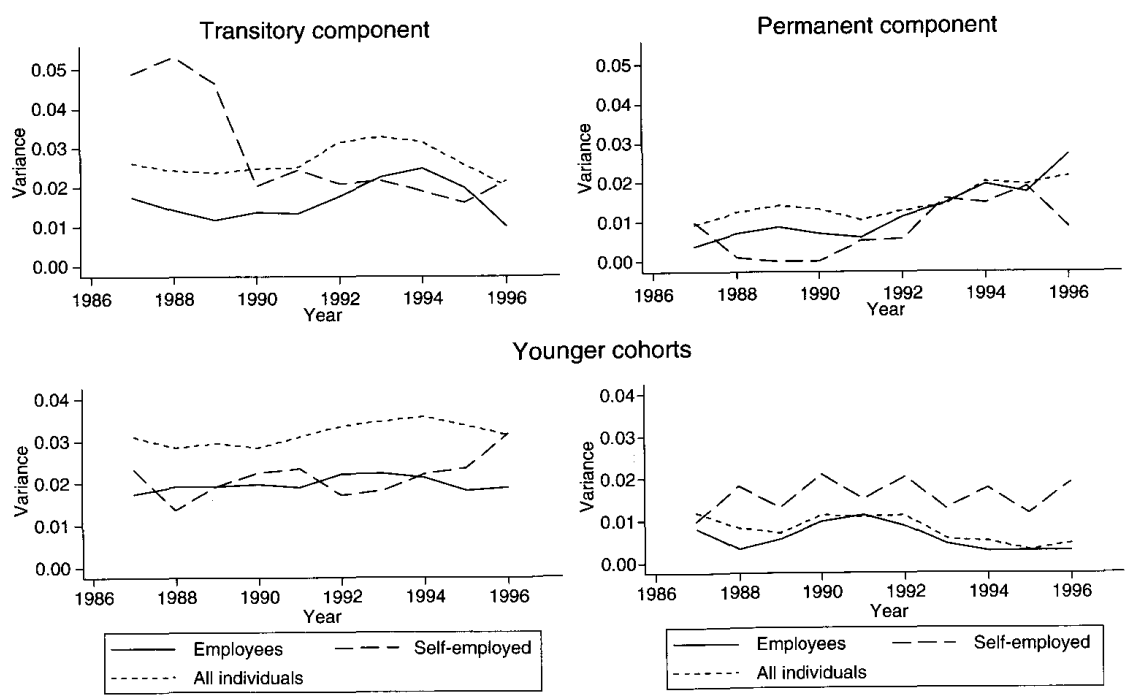

Figure 7. Variance of the transitory and permanent components, by cohort 
TABLE 8

TABLE 8

Minimum distance estimates; by cohort

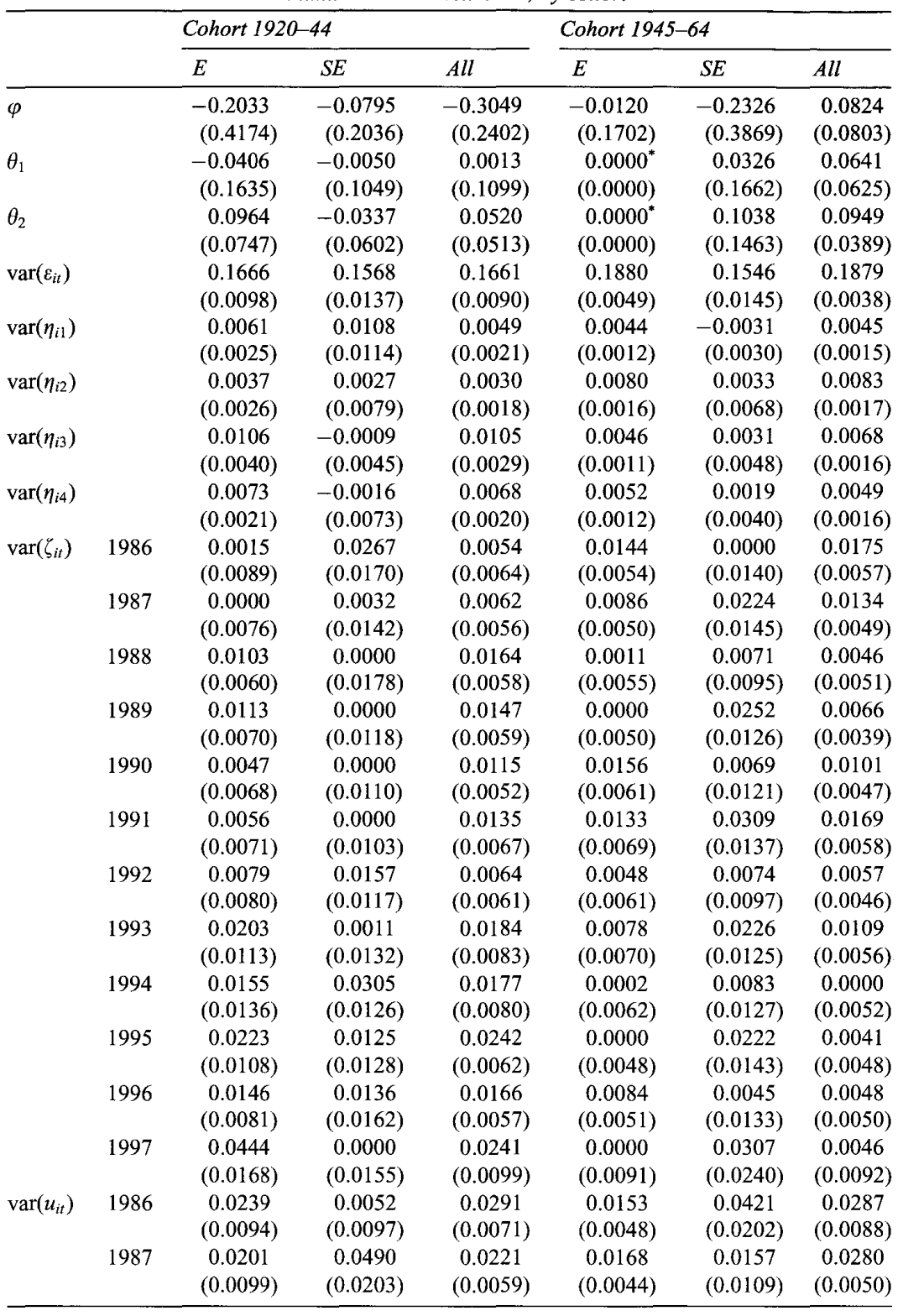

\begin{tabular}{cccccccc}
\multicolumn{7}{c}{ TABLE 8 } \\
(continued)
\end{tabular}

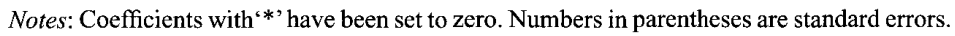

transitory components of income variance by groups defined in terms of employment status, cohort and educational level. However, sample-size limitations deter us from doing it. Alternatively, we have repeated the previous exercise by splitting the sample first by cohort and employment status and, secondly, by educational level and employment status. To the extent that differences across employees and self-employed still remain, we can be rather confident that employment status has a genuine role.

Figures 5 and 6 present the variance of log income and log consumption for employees and self-employed for each cohort (individuals born in 1920-44 or in 1945-64) ${ }^{12}$ and educational group (less or more than secondary school). We can see that both the level and the evolution of income inequality are noticeably different for employees and self-employed, especially among older and more educated individuals.

Minimum distance estimates are presented in Tables 8 and 9. Figures 7 and 8 show that in general the pattern for the employees is quite similar to the pattern for the sample including all individuals. The average relative contribution of the transitory component is considerably higher for the self-employed than for the employees in all cohorts and education groups. For instance, for the low educated that cohort entered the labour market during the period of the less dynamic dictatorship. 
TABLE 9

TABLE 9

Minimum distance estimates; by education

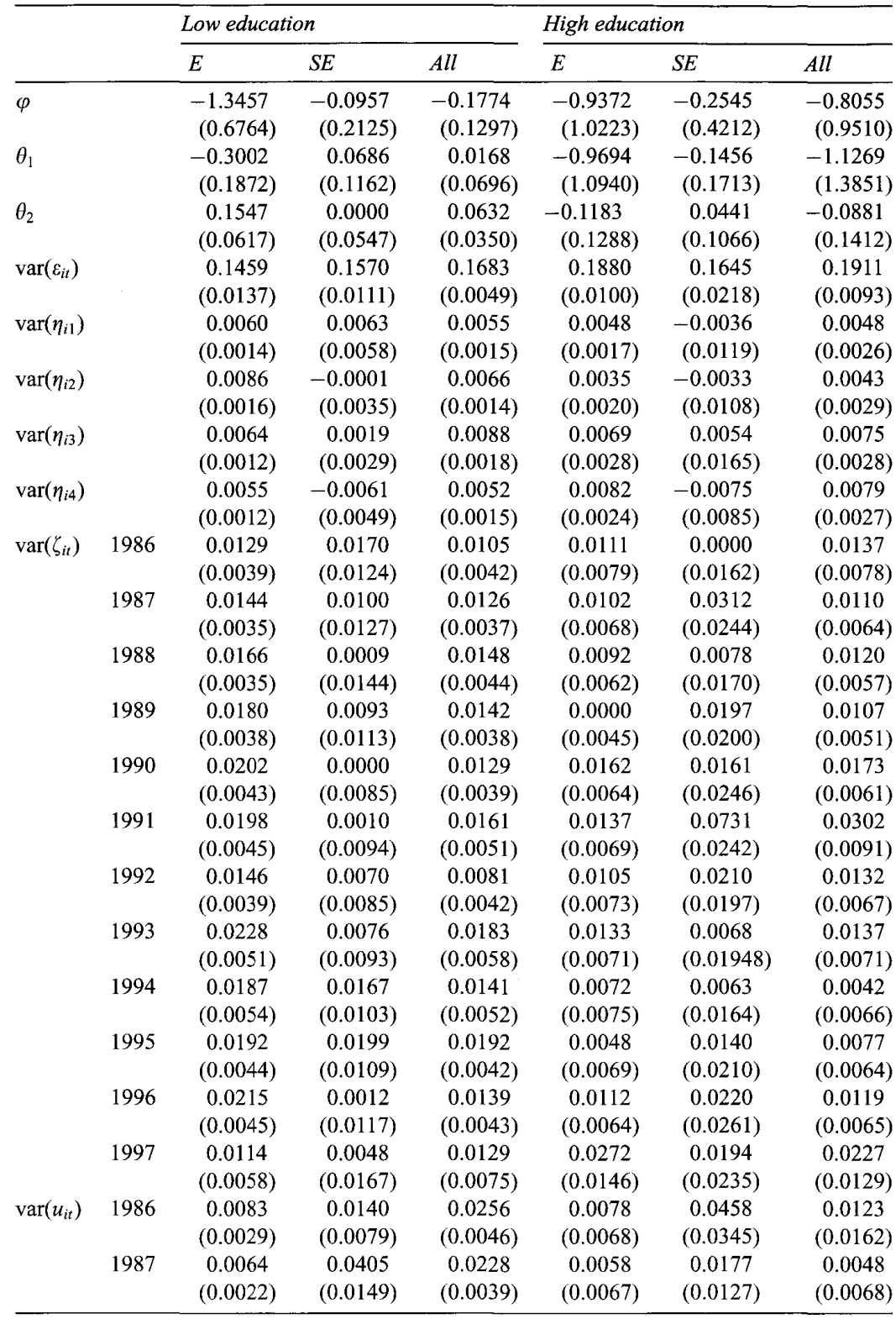

\begin{tabular}{cccccccc}
\hline & \multicolumn{1}{l}{ Low education } & & \multicolumn{3}{l}{ High education } \\
\cline { 2 - 4 } \cline { 6 - 7 } & $E$ & $S E$ & All & & $S E$ & All \\
\hline 1988 & 0.0055 & 0.0662 & 0.0321 & 0.0033 & 0.0140 & 0.0038 \\
& $(0.0019)$ & $(0.0345)$ & $(0.0062)$ & $(0.0037)$ & $(0.0116)$ & $(0.0051)$ \\
1989 & 0.0100 & 0.0195 & 0.0230 & 0.0029 & 0.0132 & 0.0031 \\
& $(0.0037)$ & $(0.0082)$ & $(0.0042)$ & $(0.0032)$ & $(0.0115)$ & $(0.0039)$ \\
1990 & 0.0089 & 0.0265 & 0.0254 & 0.0035 & 0.0668 & 0.0069 \\
& $(0.0033)$ & $(0.0086)$ & $(0.0053)$ & $(0.0037)$ & $(0.0483)$ & $(0.0089)$ \\
1991 & 0.0116 & 0.0286 & 0.0316 & 0.0061 & 0.0005 & 0.0077 \\
& $(0.0049)$ & $(0.0106)$ & $(0.0061)$ & $(0.0077)$ & $(0.0131)$ & $(0.0108)$ \\
1992 & 0.0088 & 0.0224 & 0.0266 & 0.0049 & 0.0427 & 0.0066 \\
& $(0.0029)$ & $(0.0082)$ & $(0.0052)$ & $(0.0055)$ & $(0.0254)$ & $(0.0086)$ \\
1993 & 0.0141 & 0.0203 & 0.0396 & 0.0071 & 0.0171 & 0.0085 \\
& $(0.0070)$ & $(0.0077)$ & $(0.0087)$ & $(0.0076)$ & $(0.0109)$ & $(0.0109)$ \\
1994 & 0.0078 & 0.0255 & 0.0322 & 0.0093 & 0.0189 & 0.0097 \\
& $(0.0032)$ & $(0.0077)$ & $(0.0061)$ & $(0.0122)$ & $(0.0113)$ & $(0.0133)$ \\
1995 & 0.0083 & 0.0251 & 0.0248 & 0.0037 & 0.0481 & 0.0068 \\
& $(0.0028)$ & $(0.0092)$ & $(0.0042)$ & $(0.0041)$ & $(0.0276)$ & $(0.0093)$ \\
1996 & 0.0098 & 0.0218 & 0.0276 & 0.0026 & 0.0042 & 0.0041 \\
& $(0.0037)$ & $(0.0072)$ & $(0.0059)$ & $(0.0029)$ & $(0.0097)$ & $(0.0054)$ \\
1997 & 0.0023 & 0.0423 & 0.0205 & 0.0119 & 0.0235 & 0.0080 \\
& $(0.0035)$ & $(0.0165)$ & $(0.0074)$ & $(0.0125)$ & $(0.0135)$ & $(0.0103)$ \\
\hline
\end{tabular}

Note: Numbers in parentheses are standard errors.

group it represents around $30 \%$ for employees and almost $90 \%$ for the self-employed; and for the oldest cohort these figures are $60 \%$ and $75 \%$, respectively. It is interesting to note that the variance of the permanent component for employees increased for older cohorts after 1991, whereas it decreased for younger cohorts. Therefore, towards the end of the period employees from younger cohorts faced a lower variance of permanent shocks than those from older cohorts. On the other hand, the reduction in the variance of the transitory component for the self-employed in the second half of the $1980 \mathrm{~s}$ is a phenomenon that characterized basically the older cohorts.

We have also performed a test of equality of coefficients between employees and self-employed. We cannot reject the null hypothesis of equality for some years, especially for the permanent component. Nonetheless, this result is not surprising, given the small sample size of some of the groups considered.

\section{Conclusions}

In this paper we use Spanish panel data on income and consumption to analyse the evolution of income inequality for self-employed and employees over the period 1986-97. Specifically, we analyse that the evolution and decomposition of inequality is different according to the employment status. Initially, we account only for period 

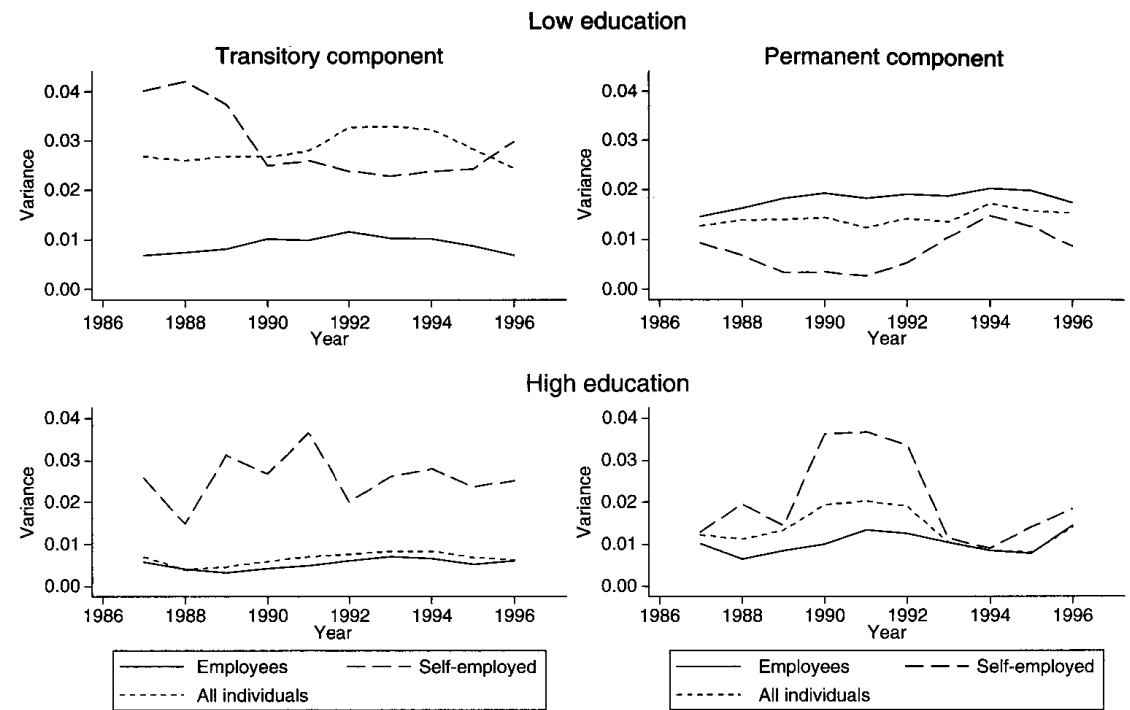

High education

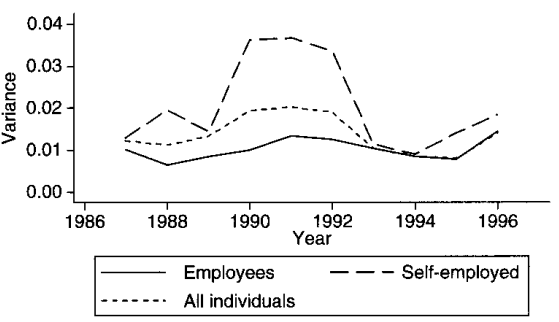

Figure 8. Variance of the transitory and permanent components, by education

effects, omitting cohort and education effects. As this could be problematic if period effects are biased differently for employees and self-employed, we also perform a robustness check to analyse whether the differences between both groups still persis when we also control for cohort and education effects. Nonetheless, more studies are needed to analyse these issues in detail.

We find that income inequality for employees follows a pattern similar to that of the sample that includes all households: it decreased until the beginning of the 1990s, went up approximately until 1994 and down again in the last 2 years of the sample. In turn for the self-employed there was a strong increase between 1986 and 1990 and a sharp decrease from 1990 to 1992 , to increase slightly at the end of the period. Note that with this type of study it is not possible to distinguish whether the evolution of income inequality is due to a composition effect (i.e. changes in the type of worker who enter the labour market) or due to changes in the risk that all individuals face.

Our results point out that the evolution of income inequality can be basically explained by the transitory component of income for the self-employed, although there is an increase in the variance of the permanent component for this group in the early 1990s. For the employees, it is mainly driven by the permanent component The observed decrease in income inequality for this group at the end of the period is mainly due to a decrease in the variance of the transitory component. There is no evidence that the transitory shocks are transmitted into consumption for any of the groups. Therefore, although the self-employed face higher income risk than the employees, it seems that they are able to insure it.
The evolution of the transitory component displays a clear co-movement with the business cycle, although of different sign for employees (anti-cyclical) and for the self-employed (pro-cyclical). The increase in the variance of the transitory component for the samples of employees and 'All' also coincides with a period of higher employment instability in Spain because of the widespread use of temporary contracts introduced around 1984. The reduction from 1993-94 coincides with the implementation of additional labour market reforms aimed at reducing the indiscriminate use of this type of contracts.

Our finding that in Spain income inequality has not increased over the period considered partly differs from the evidence for US and UK. The increase in cross-sectional inequality in these labour markets over the 1980s has been widely documented. Moffit and Gottschalk (2002), using a different methodology and PSID data, find that the variance of the transitory component of earnings increased over the 1970s and 1980s in a magnitude approximately equal to an increase in the variance of the permanent component. Dickens (2000) uses the same approach as Gottschalk and Moffit and obtains similar results for the UK in 1975-95. The results by Blundell and Preston (1998), who follow an approach similar to ours, are also consistent with those of Dickens (2000).

However, none of these papers has investigated the importance of accounting separately for self-employment income. Given that changes in income inequality driven by transitory shocks will only have small effects on consumption inequality and welfare, our results suggest that it would be useful to do a separate analysis and that the results usually reported in the literature provide misleading conclusions for the self-employed. Moreover, those policies aimed at reducing the income uncertainty for the self-employed, such as the right to receive unemployment benefits, seem well-suited to reduce transitory inequality.

\section{References}

Albarrán, P. (2000). Income Uncertainty and Precautionary Saving: Evidence from Household Rotating Panel Data, Working Papers 0008, Centro de Estudios Monetarios y Financieros.

Alvarez, J. (2004) 'Dynamics and seasonality in quarterly panel data: an analysis of earnings mobility in Spain', Journal of Business \& Economic Statistics, Vol. 22, pp. 443-457.

Baker, M. and Solon, G. (2003). 'Earnings dynamics and inequality among Canadian men, 1976-1992: evidence from longitudinal income tax records', Journal of Labor Economics, Vol. 21, pp. 289-321. Bla Of Economics, Vol 113, $\mathrm{pp}, 603$ 3 640 . of Economics, Vol. 113, pp. 603-640.

Blundell, R., Pistaferri, L. and Preston, I. (2008). 'Consumption inequality and partial insurance', . 1887-1921.

Bowning, M. and Lusardi, A. (1996). 'Household saving: micro theories and micro facts', Journal of Economic Literature, Vol. 34, pp. 1797-1855.

The role of employer/employee interactions in labor market cy. Ju, 
Cervini, P. and Ramos, X. (2006). 'Permanent and transitory earnings inequality in Spain; 1993-2000', Mimeo, Universitat Autònoma de Barcelona.

Cutanda, A. (2002). 'La medición de la desigualdad a través de un modelo de elección intertemporal', Hacienda Pública Española, Vol. 163, pp. 93-117.

Deaton, A. and Paxson, C. (1994). 'Intertemporal choice and inequality', Journal of Political Economy, Vol. 102, pp. 384-394.

Dickens, R. (2000). 'The evolution of individual male earnings in Great Britain: 1975-95', The Economic Journal, Vol. 110, pp. $27-49$.

Guvenen, F. (2005). 'An empirical investigation of labor income processes', Mimeo, University of Texas at Austin.

Hamilton, B. H. (2000). 'Does entrepreneurship pay? An empirical analysis of the returns of selfemployment', The Journal of Political Economy, Vol. 108, pp. 604-631.

Jenkins, S. P. (1995). 'Accounting for inequality trends: decomposition analyses for the UK, 1971-86' Economica, Vol. 62, pp. 29-63.

Kalwij, A. and Alessie, R. (2007). 'Permanent and transitory wages of British men, 1975-2001: year, age and cohort effects', Journal of Applied Econometrics, Vol. 22, pp. 1063-1093.

McClements, L. D. (1977). 'Equivalence scales for children', Journal of Public Economics, Vol. 8 , pp. 191-210.

Moffitt, R. A. and Gottschalk, P. (1995). Trends in the Variances of Permanent and Transitory Earning in the U.S and their Relation to Earnings Mobility. Boston College Working Papers in Economics 444, Boston College Department of Economics.

Moffitt, R. A. and Gottschalk, P. (2002). 'Trends in the transitory variance of earnings in the United States', The Economic Journal, Vol. 112, pp. C68-C73.

Parker, S. C. (1999). 'The inequality of employment and self-employment incomes: a decomposition analysis for the U.K.', Review of Income and Wealth, Vol. 45, pp. 263-274.

Parker, S. C. Belghitar, Y. and Barmby, T. (2005). 'Wage uncertainty and the labour supply of selfemployed workers', The Economic Journal, Vol. 115, pp. C190-C207.

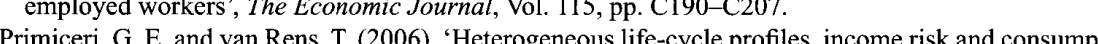
tion inequality', Mimeo, Northwestern University. 